\title{
Diabolic acids: occurrence and identification in natural products and their metabolism by simple-stomached and ruminant animals
}

\author{
BY G. P. HAZLEWOOD, A. J. NORTHROP AND R. M. C. DAWSON \\ Department of Biochemistry, ARC Institute of Animal Physiology, Babraham, \\ Cambridge CB2 4AT
}

(Received 2 June 1980 - Accepted 6 August 1980)

\footnotetext{
1. A method for gas-liquid chromatographic analysis of the dimethyl esters of a homologous series of diabolic acids is described.

2. Only when combined with low-resolution mass spectrometry could the method be used to show unequivocally the existence of diabolic acids in natural products.

3. Diabolic acids occurred naturally in rumen and faecal lipids of all ruminants examined but could not be detected in a number of ruminant tissue samples.

4. Infused ${ }^{14} \mathrm{C}$-labelled $\left(\mathrm{C}_{10: 0}\right)_{2}$ diabolic acid was poorly absorbed by both simple-stomached and ruminant animals. Oxidation was more extensive in the ruminant, but there was no evidence of deposition of diabolic acid in the tissues of either animal.
}

A series of long-chain dicarboxylic acids with vicinal dimethyl branching (the diabolic acids) occur as components of the membrane lipids in some members of the genus Butyrivibrio, including the general fatty acid auxotroph Butyrivibrio S2. In this organism, a homologous series of the dicarboxylic acids may be formed by $(\omega-1)$ condensation of a range of $n$-saturated or monounsaturated growth-promoting fatty acids (Hazlewood \& Dawson, 1979; Hauser et al. 1979; Klein et al. 1979).

Because of the ubiquitous presence of butyrivibrios in the rumen, it is likely that diabolic acids are present in the digesta passing to the lower gut of most ruminants. This raises the question of the metabolic fate of diabolic acids in ruminants.

In this paper we describe a method for the unequivocal identification of diabolic acids in biological samples with particular reference to samples obtained from various sites in the ruminant animal. In addition, we have examined the metabolic fate of biosyntheticallyprepared $\left[{ }^{14} \mathrm{C}\right]$-labelled $\left(\mathrm{C}_{16: 0}\right)_{2}$ diabolic acid in the rat and sheep.

\section{METHODS}

\section{Preparation of ${ }^{14} \mathrm{C}$-labelled and unlabelled diabolic acids}

The general fatty acid auxotroph Butyrivibrio $\mathbf{S} 2$ was cultured in a fatty acid-free basal medium as described previously (Hazlewood \& Dawson, 1979). The required fatty acid supplement $\left(30 \mu \mathrm{g} / \mathrm{ml}\right.$, unlabelled, $\left[{ }^{-14} \mathrm{C}\right]$-labelled or $\left[\mathrm{U}-{ }^{19} \mathrm{C}\right]$-labelled) was dispersed by sonication in the presence of sodium taurocholate $(400 \mu \mathrm{g} / \mathrm{ml}$ final concentration). Freshly-prepared medium was inoculated $(50 \mathrm{ml} / \mathrm{l})$ with a $24 \mathrm{~h}$ culture of $\mathrm{S} 2$ in the same medium and after $18 \mathrm{~h}$ incubation at $39^{\circ}$, cells were harvested by centrifugation and extracted with lipid solvents (Clarke et al. 1976). The procedures employed for the acid methanolysis of all lipid extracts investigated during this work and the purification of both unlabelled and ${ }^{14} \mathrm{C}$-labelled diabolic acid dimethyl esters by preparative thin layer chromatography (TLC) were as described previously (Klein et al. 1979). Methanolysis of some samples (e.g. milk lipids and total lipids of rumen contents) produced a large excess of methyl esters of fatty acids which made concentration of the diabolic acid dimethyl ester 
fraction by TLC impractical. Instead methyl esters were eluted from a silicic acid column (CC-4 special; Mallinckrodt; $20 \times 200 \mathrm{~mm}$ ) with diethyl ether-light petroleum (b.p. 40-60 $(1: 24, \mathrm{v} / \mathrm{v})$ and the diabolic acid dimethyl ester fraction was eluted in diethyl ether-light petroleum (b.p. $\left.40-60^{\circ}\right)(2: 23, v / v)$. Where required, diabolic acid dimethyl ester was converted to the free acid by refluxing for $1 \mathrm{~h}$ with $60 \mathrm{~g}$ potassium hydroxide/l ethanol-water $(95: 5, \mathrm{v} / \mathrm{v})$. After acidification with $6 \mathrm{M}-\mathrm{HCl}$ and the addition of an equal volume of water, the free dicarboxylic acid was extracted with light petroleum (b.p. $40-60^{\circ}$ ).

\section{Extraction of lipids}

The methods employed for the extraction of lipids from rumen contents, faeces, ruminant tissues and milk were based on those described by Folch et al. (1957) and Bligh \& Dyer (1959). Initial homogenization of samples in solvent was performed with an Ultra Turrax (1-2 min; Model TP18-10; Camlab, Cambridge). Lipid solutions were filtered through glass-wool to remove insoluble material and concentrated by rotary evaporation. Neutral lipids and phospholipids of milk were separated by column chromatography as described by Wooding \& Kemp (1957).

\section{Gas-liquid chromatography (GLC)}

Samples containing dimethyl esters of diabolic acids in diethyl ether were chromatographed on either a $1520 \times 6.4 \mathrm{~mm}$ or $460 \times 6.4 \mathrm{~mm}$ column of $30 \mathrm{~g} \mathrm{SE}-30 / \mathrm{kg} 100-120$ mesh Diatomite CQ (Pye Unicam Ltd, Cambridge). Separation was carried out at $265^{\circ}$ with argon as carrier gas $(30-40 \mathrm{ml} / \mathrm{min})$ in a Pye Unicam series 104 chromatograph with a flameionization detector. For quantitative GLC a $\left(\mathrm{C}_{16: 0}\right)_{2}$ diabolic acid standard was purified from Butyrivibrio S2 cultured in the presence of $\left[1-{ }^{14} \mathrm{C}\right]$-palmitic acid of known specific activity. The concentration of $\left(\mathrm{C}_{16: 0}\right)_{2}$ in the standard was further checked using the hydroxamic acid method for determination of acyl ester (Kates, 1972).

\section{Mass spectrometry}

Mass spectra were recorded on an Associated Electrical Industries MS902 instrument. Samples were admitted to the source region by using the direct insert probe at approximately $200^{\circ}$ with an electron beam energy of $70 \mathrm{eV}$.

\section{Determination of radioactivity}

Portions of lipid extract were dried under nitrogen in scintillation vials and were counted in an Analytic 92 liquid-scintillation counter (G. D. Searle \& Co. Ltd, High Wycombe) after the addition of scintillator 299 (15 ml; Packard Instrument Co. Inc.). An external standard was counted with each sample and efficiency determined by the channels-ratio technique. Tissue samples (up to $200 \mathrm{mg}$ ) were digested overnight at $39^{\circ}$ with Soluene-350 (1-2 ml; Packard Instrument Co. Inc.) and were counted after the addition of Dimilume $(15 \mathrm{ml})$. An internal standard $\left(n-\left[1-{ }^{14} \mathrm{C}\right)\right.$ hexadecane, $\left.1.916 \mu \mathrm{Ci} / \mathrm{g}\right)$ was used to determine efficiency. For highly-quenched samples, a portion of lipid extract was counted after the tissue had been homogenized in lipid solvent and extracted as described previously.

\section{Metabolic experiments}

Dimethyl ester of $\left[1,30-{ }^{14} \mathrm{C}\right]-$ or $\left[\mathrm{U}-{ }^{14} \mathrm{C}\right]-$ labelled $\left(\mathrm{C}_{16: 0}\right)_{2}$ was converted to the free acid as described previously. After evaporation under $\mathrm{N}_{2}$ the acid was taken up in a small volume $(2-5 \mathrm{ml})$ of $10 \mathrm{~g}$ potassium carbonate/ 1 solution with warming and the resultant solution was administered by stomach tube to rats under diethyl ether anaesthesia or by direct rumen injection into a sheep. The head of the animal (or in the instance of rats, the entire animal) was enclosed in a chamber connected to a respiratory-pattern analyser developed in this 


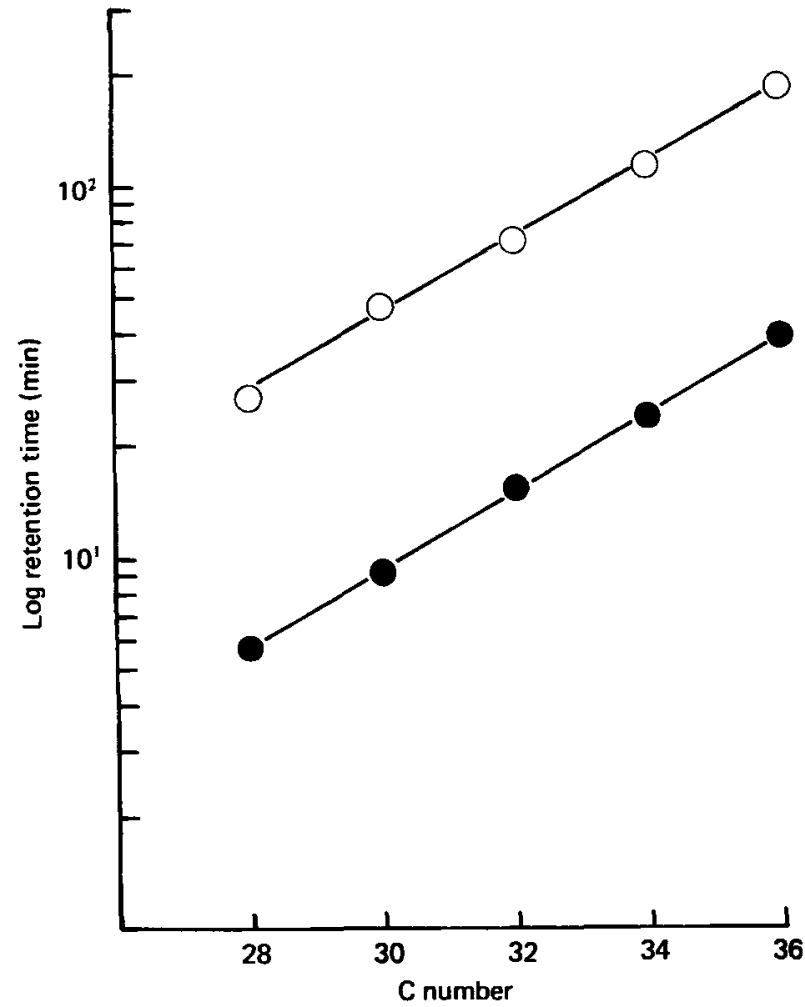

Fig. 1. Plot of $\log _{10}$ retention time $v$. C number for the dimethyl esters of a homologous series of diabolic acids chromatographed on a $1520 \mathrm{~mm}(O)$ or $460 \mathrm{~mm}(O)$ column. Diabolic acids were prepared by culturing Butyrivibrio $\mathrm{S} 2$ in the presence of the required precursor fatty acid. Lipid extraction and hydrolytic procedures and GLC-operating conditions were as described on p. 162 .

department by A. J. Northrop \& D. B. Lindsay and similar to that described by Young et al. (1975). Respired carbon dioxide was continuously monitored with an i.r. analyser (Hartmann \& Braun Ltd, Moulton Park, Northampton), and total radioactivity monitored with a Cary-Tolbert ionization chamber, and amplifier (Cary Instruments, Monrovia, Calif. USA). Outputs were fed to a pen recorder, and an integrator calibrated to provide an absolute concentration measurement. Radioactivity in ${ }^{14} \mathrm{CO}_{2}$ was determined by liquid scintillation counting after the expired air had been passed through a solution of barium hydroxide. At the termination of each metabolic experiment the animal was killed by cervical dislocation (rats) or the intravenous injection of sodium pentobarbitone (Sagatal; May \& Baker Ltd, Dagenham) (sheep).

\section{RESULTS}

Chromatographic behaviour of diabolic acids

The dimethyl esters of diabolic acids were not eluted from the column under the conditions commonly used for the GLC analysis of mixtures containing the methyl esters of long-chain fatty acids. At $265^{\circ}$ and with $30 \mathrm{~g} \mathrm{SE}-30 / \mathrm{kg}$ Diatomite CQ as the non-polar stationary phase a good separation of homologous diabolic acid dimethyl esters, prepared by culturing Butyrivibrio $\mathrm{S} 2$ in the presence of suitable fatty acid precursors, was obtained. On the normal $1520 \mathrm{~mm}$ column, the retention volume of the dimethyl ester of $\left(\mathrm{C}_{18: 0}\right)_{2}$ diabolic acid was rather large, so for routine analytical work we have employed a shorter column $(460 \mathrm{~mm})$ 
to achieve a suitable separation in less time. The standard practice of plotting log retention time v. C number for dimethyl esters of homologous diabolic acids produced straight-line relationships for both lengths of column (Fig. 1).

To test GLC operating conditions, we have routinely used as standard the dimethyl ester of undecanedioic acid, which has a retention volume of 0.28 relative to dimethyl $\left(\mathrm{C}_{16: 0}\right)_{2}$ diabolic acid under the conditions described.

\section{Natural occurrence of diabolic acids}

A combination of GLC and low-resolution mass spectrometry (LRMS) was used to demonstrate the presence of diabolic acid in hydrolysates derived from the total lipids of rumen contents and ruminant faeces. The only diabolic acid consistently found was $\left(\mathrm{C}_{\mathbf{1 6}: 0}\right)_{\mathbf{2}}$ derived, by condensation, from two molecules of palmitic acid, and although this occurred in rumen contents and faeces of all sheep examined, the amount present varied from animal to animal. For a Clun Forest wether on a diet of hay chaff $(800 \mathrm{~g})$ and oats $(200 \mathrm{~g})$ fed once daily, typical values for the occurrence of $\left(\mathrm{C}_{1 \mathrm{e:0}}\right)_{2}$ diabolic acid $18 \mathrm{~h}$ after feeding were $(\mu \mathrm{g} / \mathrm{g}$ lipid); rumen contents 632 , faeces 357 . Total lipids extracted from bovine rumen contents also contained $\left(\mathrm{C}_{16: 0}\right)_{2}$ diabolic acid, but when samples were taken from the rumen of a cow fed on a diet rich in saturated fat, there was no increase in the amount of diabolic acid formed, even though the conditions might be expected to favour the growth of organisms such as the auxotroph Butyrivibrio S2.

The removal of protozoa from rumen contents by sedimentation $\left(2 \mathrm{~h}, 39^{\circ}\right)$ or low-speed centrifugation $\left(1000 \mathrm{~g}, 1 \mathrm{~min}, 4^{\circ}\right)$ revealed that diabolic acid was associated with the bacterial fraction and to a lesser extent with the protozoa. However, protozoal fractions prepared thus are always contaminated with bacteria so it is quite likely that the associated diabolic acid was of bacterial origin.

For hydrolysates derived from the total lipids of sheep liver, kidney, subcutaneous fat and perirenal fat and the neutral and polar lipids of cows' milk, GLC analysis of the TLC fraction or silicic acid column eluate expected to contain the dimethyl esters of diabolic acids, consistently resulted in the appearance of peaks with retention volume characteristic of the dimethyl ester of $\left(\mathrm{C}_{18: 0}\right)_{2}$ diabolic acid. However, in a number of experiments, subsequent LRMS failed to provide evidence indicating the definite presence of any diabolic acid.

\section{Metabolism of $\left(\mathrm{C}_{16: 0}\right)_{2}$ diabolic acid in the rat and the sheep}

The results obtained by analysing respiratory gases and the distribution of radioactivity in tissues after the infusion of ${ }^{14} \mathrm{C}$-labelled $\left(\mathrm{C}_{16: 0}\right)_{2}$ diabolic acid into the stomach of a rat or the rumen of a sheep are shown in Table 1.

Significant oxidation of the added diabolic acid occurred during each of the three experiments performed with rats, and from Expt 2 it would appear that the greater part of the oxidation occurred within the first few hours after the infusion of the substrate. In Expt 3, [U-14C]-labelled $\left(\mathrm{C}_{18: 0}\right)_{2}$ diabolic acid was infused in an attempt to distinguish between $\beta$-oxidation and decarboxylation, but although the percentage of added radioactivity recovered as $\mathrm{CO}_{2}(\mathbf{7 . 4} \%$ compared with $39.6 \%$ for Expt 1 and $46.7 \%$ for Expt 2$)$, exceeded the theoretical yield produced by decarboxylation alone, it is not possible to say without further experiments, that the absorbed diabolic acid was completely oxidized. In all three rat experiments, the major proportion of the added diabolic acid remained in the gut contents and was not absorbed (Table 1). No significant incorporation of radioactivity into a major organ or single tissue occurred with the exception of Expt 3 where approximately $1 \%$ of the added radioactivity was recovered in the liver.

Infusion of $\left[\mathrm{U}-{ }^{14} \mathrm{C}\right]$-labelled $\left(\mathrm{C}_{16: 0}\right)_{2}$ into the rumen of a Soay sheep (Table 1) resulted 


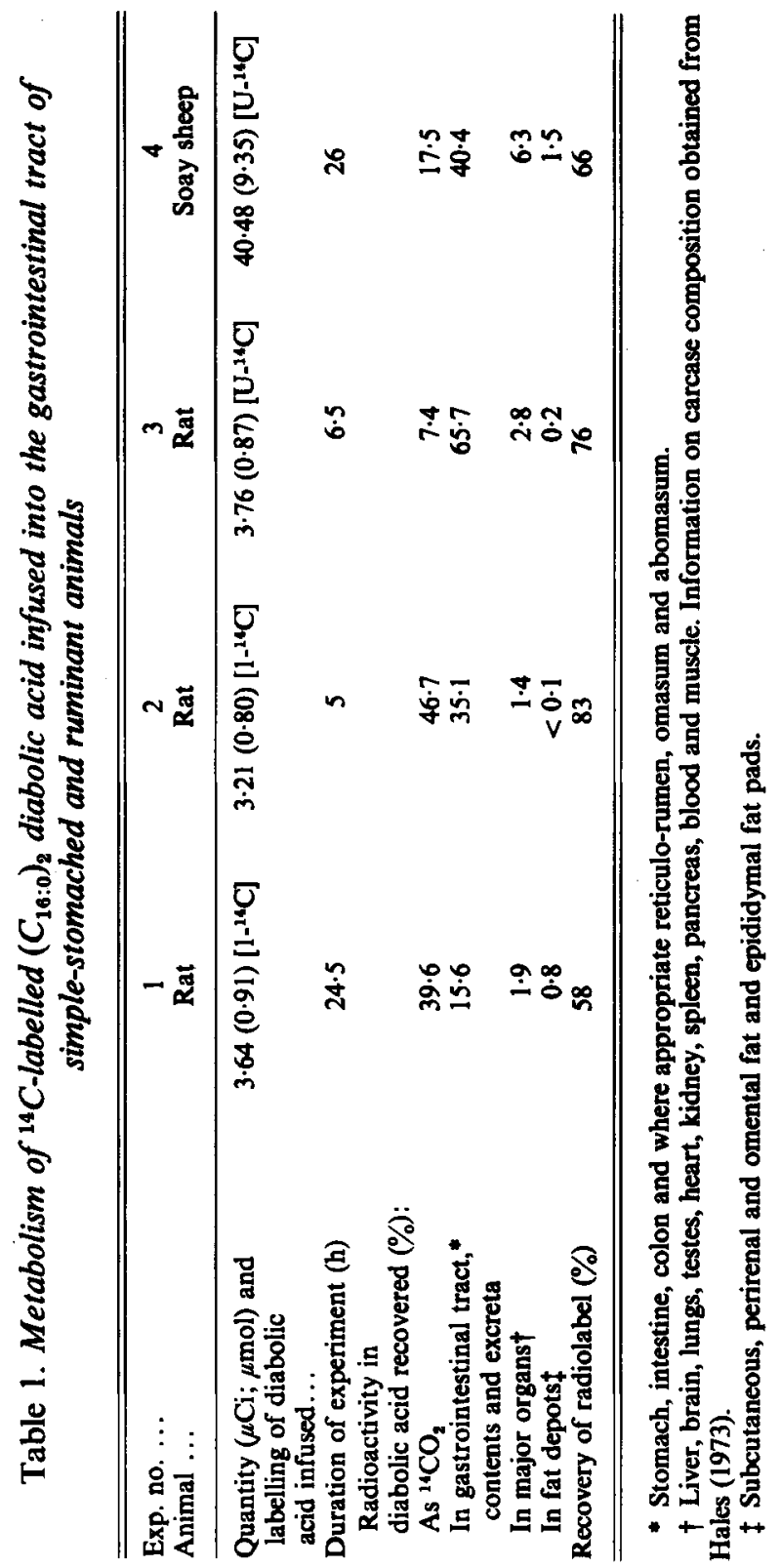


in the production of more ${ }^{14} \mathrm{CO}_{2}(17.5 \%$ of total added radioactivity) over a period of $26 \mathrm{~h}$, than could be accounted for by decarboxylation. The rate of ${ }^{14} \mathrm{CO}_{2}$ production was low, and did not change significantly throughout the experiment. Incorporation of radioactivity into blood, subcutaneous fat and muscle appeared to be greater than in the rat experiments, but nevertheless, at the termination of the experiment, more than one-third of the added radioactivity was recovered from the gut contents.

\section{DISCUSSION}

Although the fatty acid composition of total rumen lipids and the lipids of numerous species of rumen bacteria have been widely studied (see for example, Harfoot, 1978), the occurrence of diabolic acids in a genus of rumen bacteria was not reported until recently (Hazlewood \& Dawson, 1979; Klein et al. 1979). Results presented here regarding the chromatographic behaviour of these acids provide an explanation for this since traditional methods of separating fatty acid methyl esters involved use of a polar stationary phase (e.g. polyethylene glycol adipate) and an operating temperature of $180-190^{\circ}$. Under such conditions, the dimethyl esters of diabolic acids are involatile, and would not be detected. GLC clearly cannot be used to obtain unequivocal evidence of the existence of diabolic acids in biological samples since it is apparent that artefacts exist which mimic the behaviour of these acids in the GLC system described. In our experience, definitive proof for the existence of diabolic acids can only be obtained by mass spectrometry (Klein et al. 1979). The salient features of the $70 \mathrm{eV}$ mass spectra of the homologous diabolic acids are largely determined by the symmetrical nature of the molecule and the presence of fragmentation-directing vicinal dimethyl groups. Thus, on electron impact, cleavage may occur on either side of, or between the substituted $\mathrm{C}$ atoms producing two identical halves and a series of ions of the general type, $\mathrm{CH}_{3}-\mathrm{O}-\mathrm{CO}-\left[\mathrm{CH}_{2}\right]_{n}^{+}$. Also highly characteristic of the diabolic acids is the initial loss of methanol from the molecular ion to give an ion of high relative intensity at $m / e 32$ units less than the molecular ion. If one therefore considers $\left(\mathbf{C}_{18: 0}\right)_{2}$ diabolic acid, the presence in the mass spectrum of relatively intense ions at $m / e 538\left(M^{+}\right), 506,297$ and 269 could be considered unequivocal evidence.

The presence of $\left(\mathrm{C}_{16: 0}\right)_{2}$ diabolic acid in the lipids of rumen contents may be taken to indicate that Butyrivibrio S2 or bacteria like it are normally present in the rumen of both cows and sheep. That only a single homologue was detected is of interest since results of unpublished experiments have shown that Butyrivibrio S2 presented with a series of even-numbered $n$-saturated fatty acids $\left(C_{14: 0}-C_{18: 0}\right)$ synthesized predominately $\left(C_{16: 0}\right)_{2}$ diabolic acid.

The absence of diabolic acids from milk lipids and ruminant organs and fat depots, and their presence in faeces, indicates that the diabolic acid contained in bacterial lipids passing to the lower gut of the ruminant animal is either not released by lipolytic enzymes or, if released, is not totally absorbed into the circulation. Infusion experiments with ${ }^{14} \mathrm{C}$-labelled $\left(C_{16: 0}\right)_{2}$ diabolic acid indicated that the free acid is absorbed very slowly from the gut of both simple-stomached and ruminant animals and is then oxidized. In neither species was there any evidence of incorporation of diabolic acid into tissue lipids. In the sheep experiment (Expt 4$)$ the presence of a high percentage $(33 \%)$ of added radioactivity in the reticulo-rumen contents $26 \mathrm{~h}$ after infusion of diabolic acid implies selective retention, but it was noted at the time of slaughter that very little fluid was present in the rumen contents and it is possible that normal throughput of digesta may have been impaired. 


\section{REFERENCES}

Bligh, E. G. \& Dyer, W. J. (1959). Can. J. Biochem. 37, 911.

Clarke, N. G., Hazlewood, G. P. \& Dawson, R. M. C. (1976). Chem. Phys. Lipids 17, 222.

Folch, J., Lees, M. \& Sloane Stanley, G. H. (1957). J. biol. Chem. 226, 497.

Hales, J. R. S. (1973). Pflügers Archs 344, 119.

Harfoot, C. G. (1978). Prog. Lipid Res. 17, 21

Hauser, H., Hazlewood, G. P. \& Dawson, R. M. C. (1979). Nature, Lond. 279, 536.

Hazlewood, G. \& Dawson, R. M. C. (1979). J. gen. Microbiol. 112, 15.

Kates, M. (1972). In Techniques of Lipidology, p. 358 [T. S. Work and E. Work, editors]. Amsterdam, London and New York: North Holland/American Elsevier.

Klein, R. A., Hazlewood, G. P., Kemp, P. \& Dawson, R. M. C. (1979). Biochem. J. 183, 691.

Wooding, F. B. P. \& Kemp, P. (1975). J. Dairy Res. 42, 419.

Young, B. A., Kerrigan, B. \& Christopherson, R. J. (1975). Can. J. Anim. Sci. 55, 17. 